\title{
Frequency and Severity of Exacerbations of COPD Associated with Future Risk of Exacerbations and Mortality: A UK Routine Health Care Data Study
}

\author{
Hannah Whittaker', Annalisa Rubino ${ }^{2}$, Hana Müllerová ${ }^{2}$, Tamsin Morris $\mathbb{1}^{3}$, Precil Varghese ${ }^{4}$, \\ Yang $\mathrm{Xu}^{3}$, Enrico De Nigris ${ }^{5}$, Jennifer K Quint $\mathbb{D}^{1}$ \\ 'National Heart and Lung Institute, Imperial College London, London, UK; ${ }^{2}$ Epidemiology, AstraZeneca, Cambridge, UK; ${ }^{3}$ Medical and Scientific \\ Affairs, AstraZeneca, Luton, UK; ${ }^{4}$ Biopharmaceuticals Medical, Respiratory and Immunology, AstraZeneca, Gaithersburg, MD, USA; ${ }^{5} \mathrm{Health}$ \\ Economics, AstraZeneca, Cambridge, UK \\ Correspondence: Hannah Whittaker, Email h.whittaker@imperial.ac.uk
}

Background: Studies have shown that chronic obstructive pulmonary disease (COPD) exacerbation events are related to future events; however, previous literature typically reports frequent vs infrequent exacerbations per patient-year and no studies have investigated increasing number of severe exacerbations in relation to COPD outcomes.

Objective: To investigate the association between baseline frequency and severity of exacerbations and subsequent mortality and exacerbation risk in a COPD cohort.

Methods: Clinical Practice Research Datalink (CPRD) Aurum and Hospital Episode Statistics data were used to identify patients registered at general practices in the UK, who had a diagnosis of COPD, were over the age of 40 years, were smokers or ex-smokers and had data recorded from 2004 onwards. Frequency and severity of exacerbations in the baseline year were identified as moderate exacerbations (general practice events) and severe exacerbations (hospitalised events). Patients were categorised as having: none, 1 moderate only, 2 moderate only, 3+ moderate only, 1 severe (and any moderate), 2 severe (and any moderate), and 3+ severe (and any moderate exacerbations). Poisson regression was used to investigate the association between baseline exacerbation frequency/severity and exacerbation events and mortality over follow-up.

Results: Overall, 340,515 COPD patients were included. Patients had higher rates of future exacerbations with increasing frequency and severity of baseline exacerbations compared to no baseline exacerbations. Adjusted incidence rate ratios (IRR) for patients with 1, 2, and 3+ moderate exacerbations compared to 0 exacerbations were 1.70 (95\% CI 1.66-1.74), 2.31 (95\% CI 2.24-2.37), and 3.52 (95\% CI 3.43-3.62), respectively. Patients with increased frequency of baseline exacerbations were more likely to die from all-cause, COPD-related, and cardiovascular-related mortality in a graduated fashion.

Conclusion: Increasing number and severity of exacerbations were associated with increasing risk of subsequent exacerbations, allcause mortality and COPD-related mortality. Even a single moderate event increases the risk of future events, illustrating that every exacerbation counts.

Keywords: COPD, exacerbations of COPD

\section{Introduction}

Exacerbations of COPD are acute worsening of COPD symptoms (breathlessness, cough, sputum volume and purulence) beyond normal day-to-day variation that usually require treatment. Between $30 \%$ and $50 \%$ of people with COPD experience at least one exacerbation per year. ${ }^{1}$ Even a single moderate exacerbation increases risk of future multiple exacerbation events, starting a spiral of excessive disease progression and leading to an increased risk of death. ${ }^{2}$ Exacerbations have also been associated with other clinical outcomes such as accelerated lung function decline and reduced quality of life., 
Studies have shown that exacerbations are related to future exacerbations; however, little is known about their clinical burden. ${ }^{1,2,5}$ To date, most published literature reports a combined category of moderate-severe exacerbations, typically stratifying patients as experiencing frequent (ie, two or more exacerbation events per patient-year) vs infrequent (none or one) exacerbations. Very few studies have evaluated the impact of moderate or severe events only, their cumulative effect in triggering further exacerbations or focused on the incremental burden related to an increasing number of exacerbation events. Rothnie et al found that in a primary care population of COPD patients, the hazard ratio (HR) for future exacerbations was 1.71 (1.66-1.77) in patients with a previous single exacerbation and 3.41 (3.27-3.56) in patients with more than five events compared to patients with no previous events. The risk of future exacerbation increased gradually with increasing previous moderate exacerbations. ${ }^{2}$

We aimed to quantify the burden of exacerbations in a granular way, extending from and updating previous work by Rothnie et al, ${ }^{1,2}$ particularly by increasing the granularity of severe exacerbations, to investigate the association between frequency and severity of exacerbations and future exacerbations and mortality in COPD patients as well as in specific sub-groups of COPD patients who may have increased risks of future clinical events.

\section{Methods}

An observational cohort study was conducted in the UK using electronic health-care registries.

\section{Study Design and Participants}

The EXACOS-UK (EXAcerbations of COPD and their OutcomeS) study used the Clinical Practice Research Datalink (CPRD) Aurum, a primary care database of patients registered at general practices in England. Linked mortality data from the Office for National Statistics (ONS), socioeconomic data from the Index of Multiple Deprivation (IMD), and secondary care data from Hospital Episode Statistics (HES) were provided for this study by CPRD for patients in England. COPD patients were included if they met the following criteria: 1) had a diagnosis of COPD using validated codes; ${ }^{6}$ 2) were aged 40 or older; 3 ) were current or ex-smokers; 4) had data recorded in CPRD Aurum from the $1^{\text {st }}$ January 2004 onwards; and 5) were registered at a GP practice that was up-to-standard (practices deemed to be of "research quality"). ${ }^{7}$ Additionally, patients were required to have one year of baseline data after the inclusion criteria was met. Index date (start of follow-up) was the date 1-year after all other conditions were met. Follow-up was from index date until the $30^{\text {th }}$ November 2019 or earlier if patients died or were transferred to a non-CPRD contributing practice (Figure 1).

\section{Exposure and Outcomes}

The exposure of interest was frequency and severity of exacerbations identified in the baseline year prior to index date. Moderate exacerbation events were defined as events recorded in the general practice (CPRD Aurum) using a combination of exacerbation diagnosis codes, antibiotic and oral corticosteroid prescriptions prescribed together for 5-14 days, and recorded symptoms based on a previous validated definition of exacerbation in primary care. ${ }^{8}$ Severe

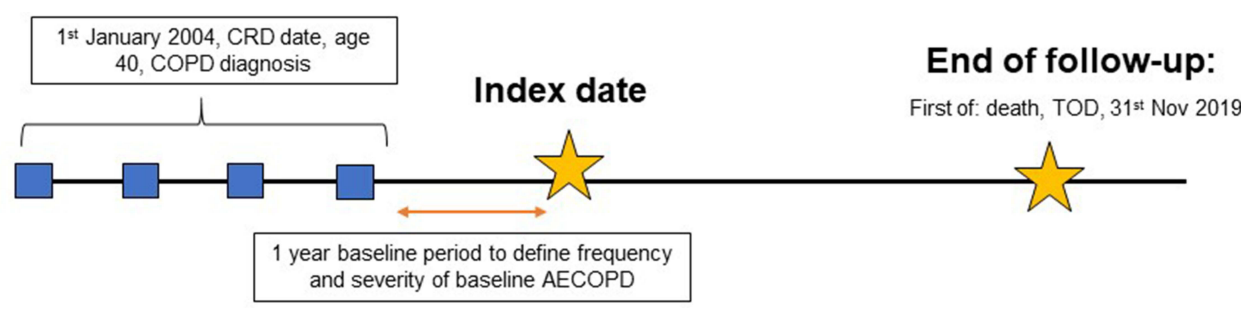

Figure I Study design

Notes: Baseline exacerbation groups include: none, I moderate (and no severe), 2 moderate (and no severe), $3+$ moderate (and no severe), I severe (and any moderate), 2 severe (and any moderate) and 3+ severe (and any moderate) defined in the year prior to index date.

Abbreviations: CRD, current registration date; AECOPD, acute exacerbation of COPD; TOD, transfer out date. 
exacerbation events were defined as COPD, and lower respiratory tract infection events leading to a hospitalisation as recorded in HES. ${ }^{9}$ Events that were recorded within 2 weeks of each other were assumed to be the same event. Baseline exacerbation frequency and severity was categorised into one of the seven categories: none, 1 moderate (and no severe), 2 moderate (and no severe), 3+ moderate (and no severe), 1 severe (and any moderate), 2 severe (and any moderate) and $3+$ severe (and any moderate). These groups were mutually exclusive. See page 2 in the supplementary materials for the "Number of moderate events in patients with severe baseline exacerbations".

Study outcomes were measured between index date and the end of follow-up. These included exacerbations (moderate or severe) and mortality. Specifically, all-cause mortality, COPD-related mortality, and cardiovascular-related mortality were extracted from the ONS mortality database using ICD10 codes.

\section{Statistical Analysis}

Baseline characteristics were described overall and by exposure sub-groups of exacerbation frequency and severity, using mean (SD) for continuous measures and numbers (\%) for categorical measures.

Baseline characteristics included age at index date, gender, smoking status (current or ex-smoker), BMI (underweight $<18.5 \mathrm{~kg} / \mathrm{m} 2$, normal $18.5-24.9 \mathrm{~kg} / \mathrm{m} 2$, overweight $25.0-29.9 \mathrm{~kg} / \mathrm{m} 2$, and obese $\geq 30.0 \mathrm{~kg} / \mathrm{m} 2$ ), depression, anxiety disorder, gastro-oesophageal reflux disease (GORD), lung cancer, myocardial infarction, heart failure, stroke, asthma recorded within five years to two years prior to start of follow-up, socioeconomic deprivation using the Index of Multiple deprivation score, modified Medical Research Council (mMRC) dyspnoea scale (0-4), GOLD-defined lung obstruction (GOLD 1: FEV1\% predicted $\geq 80 \%$; GOLD 2: FEV1\% predicted 50-79\%; GOLD 3: FEV1\% predicted 30-49\%; GOLD 4: FEV1\% predicted $<30 \%$ ), COPD medication use (including combination of long and short acting bronchodilators and ICS), and high or low blood eosinophil level (using threshold of 300 cells $/ \mu \mathrm{L}$ ). See supplementary material Table E1 for further detail on definitions of each baseline covariate.

The proportion of patients with none, 1 moderate, 2 moderate, $3+$ moderate, 1 severe, 2 severe, and $3+$ severe exacerbations for each year of follow-up were described using numbers (\%) in patients with active follow-up in each year. Poisson regression was used to investigate the association between baseline exacerbation frequency and severity and the number of subsequent exacerbations (any type of exacerbations and separately for moderate and severe exacerbations) using incidence rate ratios (IRR). Fully adjusted models included all baseline covariates.

Exploratory analyses were repeated for the following sub-populations of interest: 1) patients with eosinophils $\geq 300$ cells $/ \mu \mathrm{L}$; 2) patients with current asthma; 3 ) patients with a history of myocardial infarction, heart failure, stroke, and any other major adverse cardiac events (ie, requiring a hospitalisation for cardiovascular disease); 4) patients with GORD; and 5) patients with depression or anxiety disorder.

\section{Ethics}

This work is based in part on data from the Clinical Practice Research Datalink (CPRD) obtained under license from the United Kingdom (UK) Medicines and Healthcare products Regulatory Agency (MHRA). The data is provided by patients and collected by the National Health Service (NHS) as part of their care and support. The interpretation and conclusions contained in this study are those of the authors alone.

A protocol for this research were approved by the Independent Scientific Advisory Committee (ISAC) for MHRA Database Research (protocol number 20_103R) and the approved protocol was made available to the journal in which this research is published and to the reviewers during peer review. Generic ethical approval for observational research using the CPRD with approval from ISAC has been granted by a Health Research Authority (HRA) Research Ethics Committee (East Midlands - Derby, REC reference number 05/MRE04/87).

\section{Results}

Overall, 340,515 patients were included in the study. Figure E1 illustrates the inclusion of patients for the study cohort. Of those included 181,176 (53.2\%) patients had no exacerbations at baseline, 68,038 (20.0\%) had one moderate exacerbation only, $31,825(9.4 \%)$ had two moderate exacerbations only, 33,780 (9.9\%) had three moderate exacerbations 
only, 19,194 (5.6\%) had one severe exacerbation, 4,094 (1.2\%) had two severe exacerbations and 2,408 (0.7\%) had $\geq 3$ severe exacerbations. Frequency and severity of exacerbations over follow-up is described in Figure E2.

Baseline characteristics of patients are detailed in Table 1 and baseline medications are detailed in Table 2. Patients with $\geq 1$ severe exacerbation at baseline appeared to be older, more likely to be ex-smokers, and had more severe disease (worse GOLD grade and mMRC score), were more likely to have had a myocardial infarction event or heart failure, were more likely to be underweight, and have lower socioeconomic status compared to patients without severe exacerbations at baseline (although no formal comparative tests were performed). In terms of treatment, patients with severe exacerbations were more likely to be treated with COPD-related therapies. Specifically, they were more likely to be managed with triple inhaled therapy with proportions ranging between $43 \%$ and $55 \%$, while in patients with moderate exacerbations, the proportions ranged between $24 \%$ and $33 \%$. Mean study follow-up length differed between baseline groups whereby patients with no exacerbation had the longest follow-up of 5.3 years $(\mathrm{SD}=4.2)$ and patients with $\geq 3$ severe exacerbation had the shortest follow-up of 2.2 years $(\mathrm{SD}=2.6)$.

\section{Association Between Exacerbation Frequency and Severity at Baseline and Future Exacerbations}

During a mean follow-up duration of 5.3 years $(\mathrm{SD}=4.2)$, patients experienced a cumulative number of 1,963,268 exacerbations, of which 1,681,909 were moderate events and 281,359 were severe events.

The incidence of any, moderate or severe exacerbation during follow-up is detailed in Figure 2. Increased frequency and severity of exacerbations was associated with increased rates of future exacerbations over follow-up. Specifically, a trend was seen between increasing frequency of moderate baseline exacerbations and rate of future exacerbations and increasing frequency of severe baseline exacerbations and rate of future exacerbations compared to no baseline exacerbations. When analyses were repeated for moderate future events only, a stronger trend was seen between increasing frequency of baseline moderate events. When analyses were repeated for severe future events only, a stronger trend was seen between increasing frequency of baseline severe events (Figure 2). Tables E2-E4 report more detailed rates.

\section{Association Between Baseline Frequency and Severity of Exacerbations and Mortality} In terms of mortality, the more frequent and severe the baseline exacerbation group, the higher the rate of all-cause mortality and COPD-related mortality (Figure 3). Such a trend was less pronounced with respect to CVD-related mortality. Table E5 reports detailed rates and IRR for all-cause, COPD-related, and CVD-related mortality.

\section{Exploratory Analyses}

Analyses that investigated the association between baseline exacerbation frequency and severity and future exacerbation events were repeated in patients with specific comorbidities. Analyses were performed in patients with high blood eosinophil level (greater than 300 cells $/ \mu \mathrm{L}$ ), history of cardiovascular disease, current asthma, and in patients with anxiety, depression, or GORD. Supplementary Tables E6 and E7 report the IRR for subsequent exacerbation events in these populations in relation to baseline frequency and severity of exacerbations. A similar pattern of association between baseline exacerbation groups and future exacerbations during follow-up was seen.

\section{Discussion}

Using an observational cohort design with data from the UK CPRD Aurum database, and including patients suffering from COPD between 2004 and 2019, we found that the rate of future exacerbations increased with increasing frequency and severity of exacerbations at baseline and that baseline moderate exacerbations were more closely associated with future moderate exacerbations and baseline severe exacerbations with future severe exacerbations. We found that this pattern was similar across all sub-populations of COPD patients with high blood eosinophils, a history of cardiovascular disease, current asthma, and with anxiety disorder, depression, and GORD, suggesting that these comorbidities do not modify the association between exacerbation frequency and severity and risk of future moderate and severe 
Table I Baseline Characteristics of Patients in the Prevalent Cohort by Baseline Exacerbation Severity/Frequency Group

\begin{tabular}{|c|c|c|c|c|c|c|c|c|}
\hline \multicolumn{2}{|c|}{ Baseline Characteristics } & \multicolumn{7}{|c|}{ By Exacerbation Frequency and Severity Group at Baseline } \\
\hline & Overall & None & $\begin{array}{c}\text { Moderate, } 0 \\
\text { Severe }\end{array}$ & $\begin{array}{c}2 \text { Moderate, } 0 \\
\text { Severe }\end{array}$ & $\begin{array}{c}\text { 3oderate, } 0 \\
\text { Severe }\end{array}$ & $\begin{array}{l}\text { I Severe, Any } \\
\text { Moderate }\end{array}$ & $\begin{array}{c}2 \text { Severe, Any } \\
\text { Moderate }\end{array}$ & $\begin{array}{c}\text { 3+ Severe, Any } \\
\text { Moderate }\end{array}$ \\
\hline Patient, & $340,515(100)$ & $181,176(53.2)$ & $68,038(20.0)$ & $31,825(9.4)$ & $33,780(9.9)$ & $19,194(5.6)$ & $4,094(1.2)$ & $2,408(0.7)$ \\
\hline Mean age (SD) & $68.2(11.6)$ & $67.6(11.6)$ & $68.3(11.5)$ & $68.6(11.5)$ & $68.4(11.5)$ & $71.9(11.5)$ & $72.8(11.2)$ & $71.6(11.2)$ \\
\hline \multicolumn{9}{|l|}{ Sex } \\
\hline Male & $180,817(53.1)$ & $102,139(56.4)$ & $34,855(51.2)$ & 15,443 (48.5) & $15,235(45.1)$ & $9,800(51.1)$ & $2,092(51.1)$ & $1,253(52.0)$ \\
\hline Female & $159,698(46.9)$ & $79,037(43.6)$ & $33,183(48.8)$ & $16,382(51.5)$ & I8,545 (54.9) & $9,394(48.9)$ & $2,002(48.9)$ & $\mathrm{I}, 155(48.0)$ \\
\hline \multicolumn{9}{|l|}{ Smoking status } \\
\hline Ex-smoker & $185,4 \mid 6(54.5)$ & $95,627(52.8)$ & $36,980(54.4)$ & $17,864(56.1)$ & 19,503 (57.7) & II,4I5 (59.5) & $2,548(62.2)$ & $\mathrm{I}, 479(6 \mathrm{I} .4)$ \\
\hline Current smoker & $155,099(45.6)$ & $85,549(47.2)$ & $31,058(45.7)$ & $|3,96|(43.9)$ & I4,277 (42.3) & $7,779(40.5)$ & $\mathrm{I}, 546(37.8)$ & $929(28.6)$ \\
\hline \multicolumn{9}{|c|}{ GOLD grade of airflow limitation $(N=25 I, 7 \mid 4)$} \\
\hline I & $75,357(29.9)$ & $44,276(33.2)$ & 15,398 (29.6) & $6,620(27.5)$ & $6,120(24.1)$ & $2,426(18.6)$ & $367(14.4)$ & $150(10.9)$ \\
\hline 2 & $118,966(47.3)$ & $64,111(48.1)$ & $25,062(48.2)$ & I I,470 (47.6) & II,6II (45.7) & $5,421(41.6)$ & $908(35.7)$ & $383(27.8)$ \\
\hline 3 & $47.325(18.8)$ & 21,179 (15.9) & $9,780(18.8)$ & $5,016(20.8)$ & $6,108(24.1)$ & $3,863(29.6)$ & $892(35.1)$ & $487(35.4)$ \\
\hline 4 & $10,066(4.0)$ & $3,662(2.8)$ & I,777 (3.4) & $\mathrm{I}, 004(4.2)$ & $\mathrm{I}, 560(6.1)$ & $1,329(10.2)$ & $378(14.9)$ & $356(25.9)$ \\
\hline \multicolumn{9}{|c|}{ mMRC score $(N=177,773)$} \\
\hline 0 & $40,242(22.6)$ & $26,061(26.3)$ & $7,670(21.9)$ & $2,975(19.4)$ & $2,254(14.7)$ & $\mathrm{I}, 107(\mathrm{II} .3)$ & $\begin{array}{l}|3| \\
(6.4)\end{array}$ & $44(4.0)$ \\
\hline I & $71,583(40.3)$ & $4 I, 98 I(42.4)$ & $\mid 4,530(4 \mid .5)$ & 6,049 (39.4) & $5,521(36.0)$ & $2,899(29.5)$ & $450(22.1)$ & $153(13.8)$ \\
\hline 2 & $42,494(23.9)$ & $2 \mathrm{I}, 426(2 \mathrm{I} .6)$ & $8,670(24.7)$ & $4,04 I(26.3)$ & $4,488(29.2)$ & $2,951(30.0)$ & $620(30.5)$ & $298(26.8)$ \\
\hline 3 & $19,370(10.9)$ & $8,174(8.3)$ & $3,569(10.2)$ & $1,916(12.5)$ & $2,536(16.5)$ & $2,182(22.2)$ & $593(29.2)$ & $400(36.0)$ \\
\hline 4 & $4,084(2.3)$ & I,39I (I.4) & $\begin{array}{l}617 \\
(1.8)\end{array}$ & $\begin{array}{l}366 \\
(2.4)\end{array}$ & $\begin{array}{l}559 \\
(3.6)\end{array}$ & $\begin{array}{l}695 \\
(7.1)\end{array}$ & $240(11.8)$ & $216(19.4)$ \\
\hline \multicolumn{9}{|l|}{ Comorbidities } \\
\hline $\begin{array}{l}\text { Myocardial } \\
\text { infarction }\end{array}$ & $26,212(7.7)$ & $12,638(7.0)$ & $5, \mid 45(7.6)$ & $2,583(8.1)$ & $2,693(8.0)$ & $2,297(12.0)$ & $523(12.8)$ & $333(13.8)$ \\
\hline
\end{tabular}


Table I (Continued).

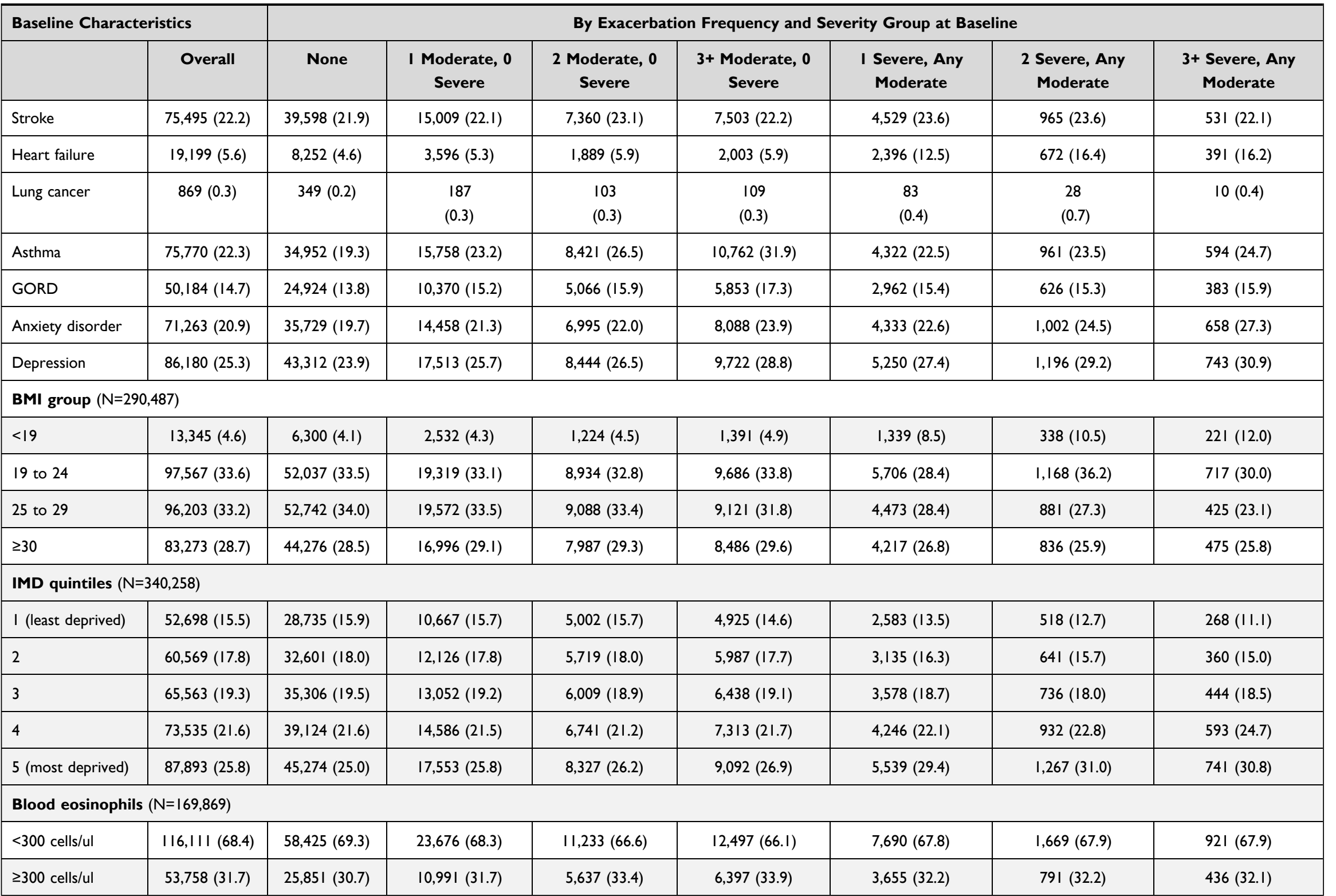

Notes: Numbers are $\mathrm{n}(\%)$ except for age which reports means (standard deviations, SD). All baseline characteristics were identified prior to index date. See supplementary material Table EI for detailed definitions of baseline characteristics and when they were identified. 
Table 2 Baseline COPD Medication of Patients in the Prevalent Cohort by Baseline Exacerbation Severity/Frequency Group

\begin{tabular}{|c|c|c|c|c|c|c|c|c|}
\hline \multicolumn{2}{|l|}{ Baseline Treatment } & \multicolumn{7}{|c|}{ By Exacerbation Severity Group at Baseline } \\
\hline & Overall & None & $\begin{array}{c}\text { I Moderate, } 0 \\
\text { Severe }\end{array}$ & $\begin{array}{c}2 \text { Moderate, } 0 \\
\text { Severe }\end{array}$ & $\begin{array}{c}\text { 3+ Moderate, } 0 \\
\text { Severe }\end{array}$ & $\begin{array}{l}\text { I Severe, Any } \\
\text { Moderate }\end{array}$ & $\begin{array}{c}2 \text { Severe, Any } \\
\text { Moderate }\end{array}$ & $\begin{array}{c}\text { 3+ Severe, Any } \\
\text { Moderate }\end{array}$ \\
\hline Patient, n (\%) & $\begin{array}{c}\mathrm{N}=340,515 \\
(100)\end{array}$ & $N=181,176(53.2)$ & $N=68,038(20.0)$ & $\mathrm{N}=3 \mathrm{I}, 825(9.4)$ & $\mathrm{N}=33,780(9.9)$ & $N=19,194(5.6)$ & $\mathrm{N}=4094(1.2)$ & $N=2408(0.7)$ \\
\hline Any & $286,422(84.1)$ & $14 \mid, 782(78.3)$ & $59,286(87.1)$ & $28,962(91.0)$ & $31,978(94.7)$ & $18, \mid 45(94.5)$ & $3,948(96.4)$ & $2,321(96.4)$ \\
\hline No medication* & $54,093(15.9)$ & $39,394(21.7)$ & $8,752(12.9)$ & $2,863(9.0)$ & $\mathrm{I}, 802(5.3)$ & $\mathrm{I}, 049(5.5)$ & $\begin{array}{l}146 \\
(3.6)\end{array}$ & $\begin{array}{c}87 \\
(3.6)\end{array}$ \\
\hline \multicolumn{9}{|c|}{ Specific COPD maintenance therapies } \\
\hline LABA monotherapy & $\begin{array}{c}8,786 \\
(3.7)\end{array}$ & $\begin{array}{l}4,740 \\
(4.2)\end{array}$ & $\mathrm{I}, 930(4.0)$ & $\begin{array}{l}834 \\
(3.4)\end{array}$ & $\begin{array}{l}818 \\
(2.9)\end{array}$ & $\begin{array}{l}377 \\
(2.3)\end{array}$ & $\begin{array}{c}62 \\
(1.7)\end{array}$ & $\begin{array}{l}25 \\
(1.1)\end{array}$ \\
\hline LAMA monotherapy & $29,484(12.5)$ & $18,679(16.7)$ & $5,499(11.4)$ & $2,098(8.6)$ & $\mathrm{I}, 60 \mathrm{I}(5.6)$ & $\mathrm{I}, 340(8.1)$ & $\begin{array}{l}207 \\
(5.6)\end{array}$ & $\begin{array}{l}60 \\
(2.7)\end{array}$ \\
\hline ICS monotherapy & $4 I, 7 \mid 3(17.7)$ & $21,172(18.9)$ & $9,481(19.6)$ & $4,670(19.1)$ & $4,427(15.5)$ & I,573 (9.5) & $\begin{array}{l}273 \\
(7.4)\end{array}$ & $\begin{array}{l}117 \\
(4.8)\end{array}$ \\
\hline LABA/ICS dual therapy & $80,306(34.0)$ & $36,136(32.2)$ & $16,994(35.2)$ & $9,146(37.4)$ & II,020 (38.5) & $5,|7|(31.3)$ & $\mathrm{I}, \mathrm{I} 27(30.3)$ & $712(32.1)$ \\
\hline LAMA/ICS dual therapy & $\begin{array}{l}6,539 \\
(2.8)\end{array}$ & $\begin{array}{l}2,907 \\
(2.6)\end{array}$ & $\mathrm{I}, 434(3.0)$ & $\begin{array}{l}734 \\
(3.0)\end{array}$ & $\begin{array}{l}938 \\
(3.3)\end{array}$ & $\begin{array}{l}401 \\
(2.4)\end{array}$ & $\begin{array}{c}91 \\
(2.5)\end{array}$ & $\begin{array}{l}34 \\
(1.5)\end{array}$ \\
\hline LABA/LAMA dual therapy & $\begin{array}{l}9,300 \\
(4.0)\end{array}$ & $\begin{array}{c}5,778 \\
(5.2)\end{array}$ & $\mathrm{I}, 628(3.4)$ & $\begin{array}{l}619 \\
(2.5)\end{array}$ & $\begin{array}{l}473 \\
(1.7)\end{array}$ & $\begin{array}{l}618 \\
(3.7)\end{array}$ & $\begin{array}{l}140 \\
(3.8)\end{array}$ & $\begin{array}{l}44 \\
(2.0)\end{array}$ \\
\hline Triple therapy & $59,980(25.4)$ & $22,805(20.3)$ & II,328 (23.5) & $6,364(26.0)$ & $9,380(32.7)$ & $7,062(42.7)$ & $\mathrm{I}, 815(48.9)$ & $\mathrm{I}, 226(55.3)$ \\
\hline \multicolumn{9}{|c|}{ Short acting bronchodilators } \\
\hline$S A B A^{\$}$ & $227,503(88.7)$ & I I0,805 (90.0) & $47,567(99.6)$ & $23,346(87.2)$ & $26,085(86.7)$ & $14,605(86.3)$ & $3,208(86.2)$ & $\mathrm{I}, 887(86.2)$ \\
\hline SAMA $\$$ & $\begin{array}{l}7,038 \\
(2.7)\end{array}$ & $\begin{array}{c}3,834 \\
(3.1)\end{array}$ & I,585 (3.0) & $\begin{array}{l}736 \\
(2.8)\end{array}$ & $\begin{array}{l}607 \\
(2.0)\end{array}$ & $\begin{array}{l}216 \\
(1.3)\end{array}$ & $\begin{array}{l}39 \\
(1.1)\end{array}$ & $\begin{array}{l}21 \\
(1.0)\end{array}$ \\
\hline SAMA/SABA ${ }^{\$}$ & $21,924(8.6)$ & $\begin{array}{r}8,456 \\
(6.9)\end{array}$ & $4,55 I(8.5)$ & $2,683(10.0)$ & $3,380(1 \mathrm{I} .2)$ & $2096(13.4)$ & $476(12.8)$ & $282(12.9)$ \\
\hline
\end{tabular}

Notes: All baseline characteristics were identified prior to index date. See supplementary material Table EI for definitions of baseline characteristics and when they were identified. No inhaled treatment defined as no SAMA or SABA combinations and no LABA, LAMA, and ICS combinations in the year prior to start of follow-up. Dual and triple therapies included both fixed doses and combination of mono and dual inhalers. *None of any medications listed below. $\$_{n}(\%)$ described for SAMA, SABA, and SAMA/SABA are not mutually exclusive as patients can take these alongside other COPD related medications described in the table. 

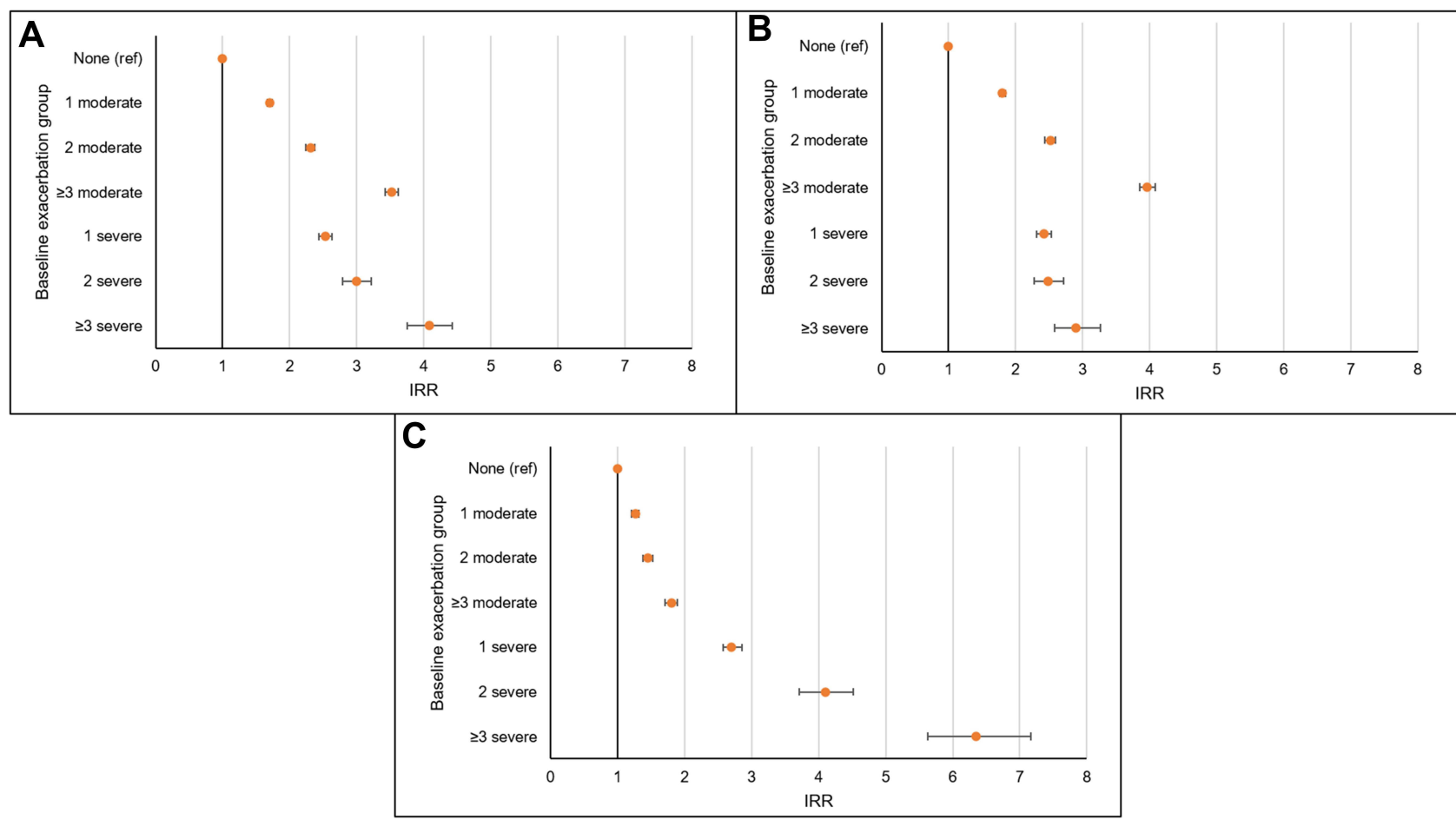

Figure 2 Incidence rate ratios (IRR) for the association between baseline frequency and severity of exacerbations and rate of (A) any future exacerbations, (B) moderate exacerbations, and $(\mathbf{C})$ severe exacerbations.

Notes: IRR (incidence rate ratios) are adjusted for age, gender, smoking status, BMI, depression, anxiety disorder, gastro-oesophageal reflux disease (GORD), lung cancer, myocardial infarction, heart failure, stroke, current asthma, socioeconomic deprivation, mMRC, GOLD-defined lung obstruction, COPD medication use, and blood eosinophil level. Baseline exacerbation groups include: none, I moderate (and no severe), 2 moderate (and no severe), 3+ moderate (and no severe), I severe (and any moderate), 2 severe (and any moderate) and 3+ severe (and any moderate) defined in the year prior to index date.

exacerbations. Lastly, we found that increasing frequency and severity of baseline exacerbations were associated with increased rate of all-cause, COPD-related, and CVD-mortality.

The association between exacerbations and risk of future exacerbations has been previously investigated in both randomised control trials and observational studies. ${ }^{1,10-12}$ Overall, increased frequency of exacerbations has been shown to be associated with increased risk of future exacerbations and is one of the most important predictors of subsequent exacerbations in the following year. ${ }^{13}$

In addition, a previous study by Rothnie et al investigated the association between increasing frequency of moderate exacerbations and risk of future exacerbations in a primary care population of COPD patients in England. Authors found that the rate of exacerbations was stable from 2004 to 2012 and that increasing frequency of moderate exacerbations was associated with increased risk of future exacerbations over a maximum 8-year follow-up period. ${ }^{2}$ Our study showed that the risk associated with the different baseline exacerbation groups (ordered in terms of increasing frequency and severity) increased in a linear fashion, similar to Rothnie, with the exception of the $\geq 3$ moderate exacerbation group which had a stronger association with future exacerbations (for any and moderate future exacerbation). Whilst findings are similar to those by Rothnie et al, where severe and moderate exacerbations behave in a similar way, there are some differences in our study. Firstly, we used an extended observational period to include more recent years. Secondly, whilst Rothnie et al found that the trend in risk of future exacerbations increased with granular categories of moderate exacerbations, we extended these findings to show the trend in risk with increasing categories of both moderate and severe baseline exacerbations.

Increased frequency and severity of the baseline exacerbation history was associated with increased rate of all-cause mortality and COPD-related death. In terms of CVD mortality, a trend was seen for increased frequency of moderate exacerbations and severe exacerbations up to two events; however, patients with three or more severe exacerbations at baseline were not more likely to die from CVD than those with no exacerbations. This is possibly because the more 


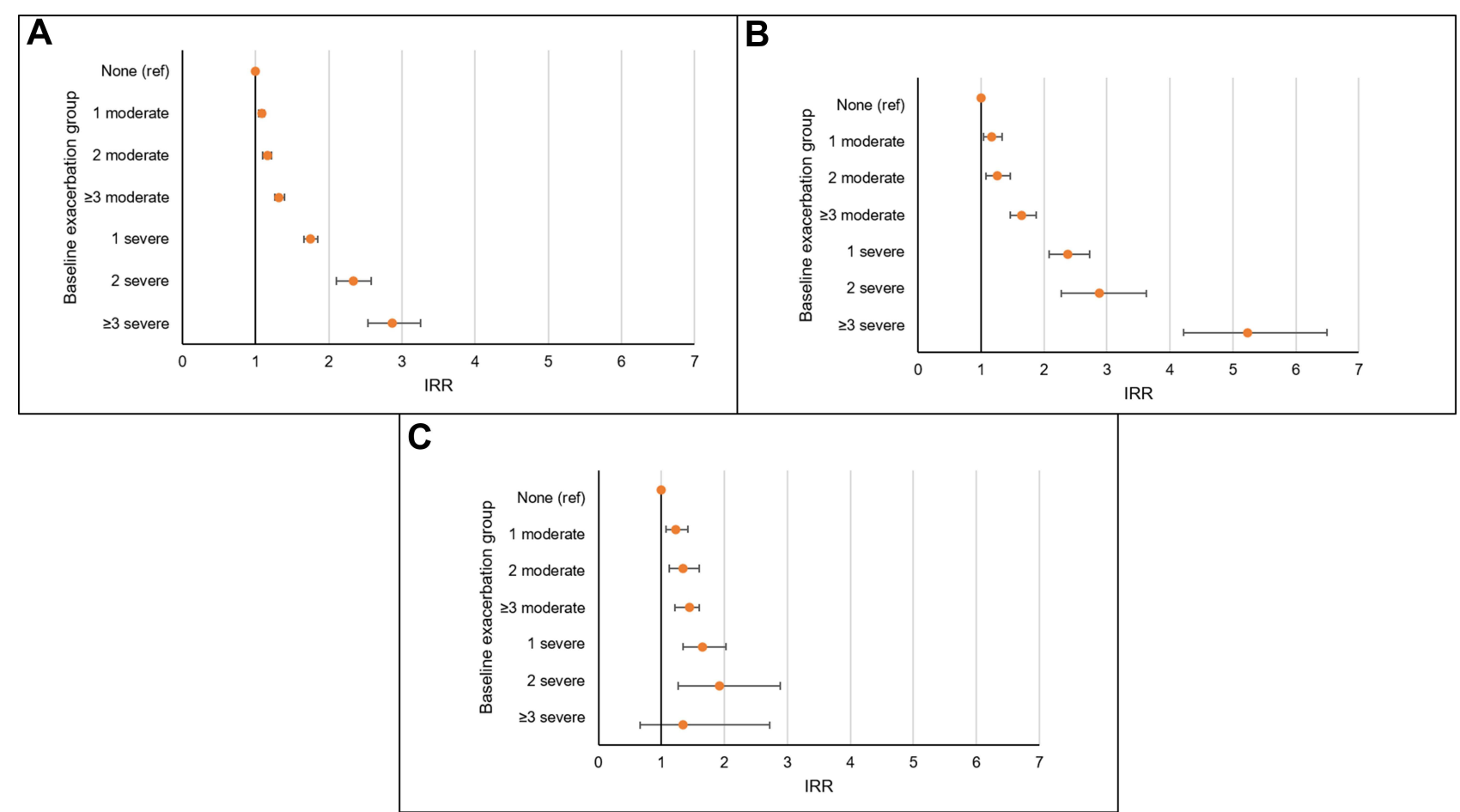

Figure 3 Incidence rate ratios (IRR) for the association between baseline frequency and severity of exacerbations and rate of (A) all-cause mortality, (B) COPD-related mortality, and (C) CVD-related mortality.

Notes: IRR (incidence rate ratios) are adjusted for age, gender, smoking status, BMI, depression, anxiety disorder, gastro-oesophageal reflux disease (GORD), lung cancer, myocardial infarction, heart failure, stroke, current asthma, socioeconomic deprivation, mMRC, GOLD-defined lung obstruction, COPD medication use, and blood eosinophil level. Baseline exacerbation groups include: none, I moderate (and no severe), 2 moderate (and no severe), 3+ moderate (and no severe), I severe (and any moderate), 2 severe (and any moderate) and $3+$ severe (and any moderate) defined in the year prior to index date.

frequent and severe the exacerbations, the more likely patients are to have COPD as the cause of death on the death certificate. Interestingly, in a UK primary care COPD population study, over a 10-year time period similar to this, COPD was the commonest cause of death in this population and remained stable over time whereas cardiovascular disease, as the cause of death, decreased slightly over the time period. ${ }^{14}$ Other explanations may include "survivor" bias, where patients with complex comorbidities may die prior reaching severe stages of their disease. Further research in this area is needed to better understand the association between increasing frequency and severity of exacerbation events and cardiovascular mortality. Previous studies found that increased frequency of exacerbations was associated with increased all-cause mortality in a Danish population of COPD patients admitted to hospital. ${ }^{15}$ It is important to note that these patients represent a subgroup of COPD patients, those hospitalised for COPD. Rothnie et al additionally found that increasing frequency of moderate exacerbations was associated with increased all-cause mortality in a generalisable population of COPD patients, and a higher risk was seen in those with at least one severe exacerbation; however, frequency of severe exacerbations was not investigated. ${ }^{2}$

Over time, there have been campaigns in the UK, for example from the British Lung Foundation and Public Health England around identifying the "missing millions" and increased case finding initiatives. This could have led to people having milder COPD at the time of diagnosis over the course of the study. ${ }^{16-18}$ Whilst exacerbations occur across all disease severities, people with COPD are less likely to exacerbate with milder disease and the milder they are, the longer they will go before having an exacerbation. Despite this, the proportion of patients with severe exacerbations remained constant over time. These patients might have had severe disease at the time of diagnosis and given there have not been any COPD disease modifying treatments in the last 15 years, the proportion of patients with severe exacerbations is unlikely to change. In more recent years, seeing a general practitioner (GP) has become harder for some patients which means that they might go straight to the hospital, through A\&E, to seek healthcare when they could have been managed in the community. Individual behaviour is such that if they do this for one exacerbation, they are likely to do it for all. 
The Royal College of General Practitioners found that the number of patients able to see their GP fell by $27.5 \%$ between 2012 and 2017. ${ }^{19}$ It is important to note that this change from 2012 might not be clinically significant. Despite this, the changes seen after the study period of the Rothnie paper highlight the relevance of this piece of work by adding to the duration of follow-up with what is already known.

\section{Strengths and Limitations}

Our study included a large sample of UK COPD patients commonly seen in primary care and included more granular categories of severe exacerbations at baseline compared to previous studies. Our work additionally extended on from previous work by including a longer, more recent follow-up period. Despite this, limitations exist.

It is important to note that not every exacerbation defined as severe (requiring a hospitalisation) might be a truly severe event and patients might have been misclassified as having a severe event when in reality they had a moderate event. Access to the general practice and the way in which people seek healthcare plays a role. Patients may not be able to access their GP as easily in more recent years and therefore might seek healthcare at the hospital rather than waiting to see their GP. Whilst these patients may have their exacerbation recorded in hospital, resulting in a "severe exacerbation" phenotype in this study, they might have had a moderate exacerbation which could not be managed otherwise that in the inpatient setting.

Furthermore, baseline characteristics, specifically mMRC, BMI, and GOLD grade for airflow obstruction had a large proportion of missing data. This meant that the fully adjusted analyses included only patients who had all baseline characteristics. This could have biased our results and should be noted. Finally, we acknowledge that clinical guidelines for treatment in primary care are not always adhered to and there might be other factors that influence a clinician's decision to treat patients.

\section{Conclusion}

Increasing frequency and severity of exacerbations are associated with increased rates of future exacerbations and mortality in primary care COPD patients. Interestingly, even one moderate exacerbation increased the rate of future exacerbations; however, it seems that patients with 3 or more moderate exacerbations are at a similar risk of future exacerbation compared to those with multiple severe exacerbations.

\section{Data Sharing Statement}

Linked pseudonymised mortality data from the Office for National Statistics (ONS), socioeconomic data from the Index of Multiple Deprivation (IMD), and secondary care data from Hospital Episode Statistics (HES) were provided for this study by CPRD for patients in England. Data is linked by NHS Digital, the statutory trusted third party for linking data, using identifiable data held only by NHS Digital. Select general practices consent to this process at a practice level, with individual patients having the right to opt-out. Use of HES and ONS data is Copyright (C) (2018), re-used with the permission of The Health \& Social Care Information Centre, all rights reserved.

Data are available on request from the CPRD. Their provision requires the purchase of a license, and this license does not permit the authors to make them publicly available to all. This work used data from the version collected in March 2020 and has clearly specified the data selected each Methods section. To allow identical data to be obtained by others, via the purchase of a license, the code lists will be provided upon request. Licenses are available from the CPRD (http://www.cprd.com): The Clinical Practice Research Datalink Group, The Medicines and Healthcare products Regulatory Agency, 10 South Colonnade, Canary Wharf, London E14 4PU.

\section{Acknowledgments}

This study was funded by AstraZeneca. This work is based on data from the Clinical Practice Research Datalink (CPRD) obtained under license from the United Kingdom (UK) Medicines and Healthcare products Regulatory Agency (MHRA). The data is provided by patients and collected by the National Health Service (NHS) as part of their care and support. The interpretation and conclusions contained in this study are those of the authors alone. 


\section{Disclosure}

JKQ has received grants from The Health Foundation, MRC, GSK, Bayer, BI, AUK-BLF, Chiesi, and AZ, and personal fees for advisory board participation or speaking fees from GlaxoSmithKline, Boehringer Ingelheim, AstraZeneca and Bayer. HW has nothing to disclose. AR, HM, TM, and YX are employees of AstraZeneca and holds stock and/or options in the company. PV and EdN are both former employees of AstraZeneca, but were employed by AstraZeneca at the time of the study. The authors report no other conflicts of interest in this work.

\section{References}

1. Hurst JR, Vestbo J, Anzueto A, et al. Susceptibility to exacerbation in chronic obstructive pulmonary disease. $N$ Engl J Med. 2010;363 (12):1128-1138. doi:10.1056/NEJMoa0909883

2. Rothnie KJ, Müllerová H, Smeeth L, et al. Natural history of chronic obstructive pulmonary disease exacerbations in a general practice-based population with chronic obstructive pulmonary disease. Am J Respir Crit Care Med. 2018;198(4):464-471. doi:10.1164/rccm.201710-2029OC

3. Miravitlles M, Ferrer M, Pont A, et al. Effect of exacerbations on quality of life in patients with chronic obstructive pulmonary disease: a 2 year follow up study. Thorax. 2004;59(5):387-395. doi:10.1136/thx.2003.008730

4. Donaldson GC, Seemungal TA, Bhowmik A, Wedzicha J. Relationship between exacerbation frequency and lung function decline in chronic obstructive pulmonary disease. Thorax. 2002;57(10):847-852. doi:10.1136/thorax.57.10.847

5. Seemungal TA, Donaldson GC, Paul EA, et al. Effect of exacerbation on quality of life in patients with chronic obstructive pulmonary disease. Am J Respir Crit Care Med. 1998;157(5):1418-1422.

6. Quint JK, Mullerova H, DiSantostefano RL, et al. Validation of chronic obstructive pulmonary disease recording in the Clinical Practice Research Datalink (CPRD-GOLD). BMJ Open. 2014;4(7):e005540. doi:10.1136/bmjopen-2014-005540

7. Wolf A, Dedman D, Campbell J, et al. Data resource profile: clinical Practice Research Datalink (CPRD) Aurum. Int J Epidemiol. 2019;48 (6):1740-1740g. doi:10.1093/ije/dyz034

8. Rothnie KJ, Müllerová H, Hurst JR, et al. Validation of the recording of acute exacerbations of COPD in UK Primary Care Electronic Healthcare Records. PLoS One. 2016;11(3):e0151357. doi:10.1371/journal.pone.0151357

9. Rothnie KJ, Müllerová H, Thomas SL, et al. Recording of hospitalizations for acute exacerbations of COPD in UK electronic health care records. Clin Epidemiol. 2016;8:771-782. doi:10.2147/CLEP.S117867

10. Sadatsafavi M, Xie H, Etminan M, et al. The association between previous and future severe exacerbations of chronic obstructive pulmonary disease: updating the literature using robust statistical methodology. PLoS One. 2018;13(1):e0191243-e0191243. doi:10.1371/journal. pone. 0191243

11. Hartley BF, Barnes NC, Lettis S, et al. Risk factors for exacerbations and pneumonia in patients with chronic obstructive pulmonary disease: a pooled analysis. Respir Res. 2020;21(1):5. doi:10.1186/s12931-019-1262-0

12. Müllerová H, Shukla A, Hawkins A, et al. Risk factors for acute exacerbations of COPD in a primary care population: a retrospective observational cohort study. BMJ Open. 2014;4(12):e006171. doi:10.1136/bmjopen-2014-006171

13. Margüello MS, Garrastazu R, Ruiz-Nuñez M, et al. Independent effect of prior exacerbation frequency and disease severity on the risk of future exacerbations of COPD: a retrospective cohort study. NPJ Prim Care RespirMed. 2016;26(1):16046. doi:10.1038/npjpcrm.2016.46

14. Gayle AV, Axson EL, Bloom CI, et al. Changing causes of death for patients with chronic respiratory disease in England, 2005-2015. Thorax. 2019;74(5):483. doi:10.1136/thoraxjnl-2018-212514

15. Schmidt SAJ, Johansen MB, Olsen M, et al. The impact of exacerbation frequency on mortality following acute exacerbations of COPD: a registry-based cohort study. BMJ Open. 2014;4(12):e006720. doi:10.1136/bmjopen-2014-006720

16. Falzon C, Soljak M, Elkin SL, Blake ID. Finding the missing millions - the impact of a locally enhanced service for COPD on current and projected rates of diagnosis: a population-based prevalence study using interrupted time series analysis. Primary Care Respir J. 2013;22(1):59-63.

17. Roberts J, Gaduzo S. Finding the 'missing millions': do we need incentives to optimise COPD outcomes? Prim Care Respir J. 2013;22(1):12-13. doi:10.4104/pcrj.2013.00024

18. Haroon S, Adab P, Griffin C, et al. Case finding for chronic obstructive pulmonary disease in primary care: a pilot randomised controlled trial. $\mathrm{Br}$ J General Pract. 2013;63(606):e55. doi:10.3399/bjgp13X660788

19. Practitioners, R.C.o.G. Fit for the Future: A Vision for General Practice; 2019.

International Journal of Chronic Obstructive Pulmonary Disease

Dovepress

\section{Publish your work in this journal}

The International Journal of COPD is an international, peer-reviewed journal of therapeutics and pharmacology focusing on concise rapid reporting of clinical studies and reviews in COPD. Special focus is given to the pathophysiological processes underlying the disease, intervention programs, patient focused education, and self management protocols. This journal is indexed on PubMed Central, MedLine and CAS. The manuscript management system is completely online and includes a very quick and fair peer-review system, which is all easy to use. Visit http://www. dovepress.com/testimonials.php to read real quotes from published authors.

Submit your manuscript here: https://www.dovepress.com/international-journal-of-chronic-obstructive-pulmonary-disease-journal 